\title{
Ensuring generation adequacy with firm energy call options-A case study for the hydro-dependant Colombian system*
}

\author{
Julio Villarreal ${ }^{1 \dagger}$, Carlos Soto $^{2}$ \\ Industrial Engineering Department at Engineering School of Universidad De Los Andes, Colombia
}

(Received October 11 2006, Accepted January 19 2007)

\begin{abstract}
Ensuring generation adequacy has been an issue for regulators all over the world. Guaranteeing the necessary quantities at an efficient price is not an easy feat in the electricity field. In Colombia, the situation is further aggravated by a generating sector mostly made out of hydraulic plants, representing close to $70 \%$ of the total capacity. These are highly susceptible to climatic shocks typical of the region, particularly the El Niño Southern Oscillation, which has, in the past, been the culprit of severe blackouts that have lasted for well over a year. The following paper evaluates the proposal made by the Colombian regulator which introduces a reliability call option with firm energy as the underlying asset as a means of ensuring generation adequacy.
\end{abstract}

Keywords: capacity charge, reliability call option, generation adequacy

\section{Introduction}

The discussion on the best method to replace the current Capacity Charge is currently taking place in Colombia. The new model to be adopted by the Colombian regulators will be of vital importance to the country, as it should provide the necessary incentives to guarantee the appropriate level of backup capacity to overcome a critical period, as well as ensuring an adequate and efficient price for this reliability.

In Colombia the reform in the electricity sphere meant that the generating sector would be privately owned and that the role of the regulator would be to generate the incentives necessary in order to ensure a reliable and efficient supply of electricity for the country, but under no circumstances would the government build new capacity. It is also worth noting that, although electricity is a private good, reliability is a public one, which translates into an obligation for the regulator.

Due to the large water resources that the country has, the ideal choice for generating capacity seemed to be large hydro projects which have very little running costs. However, after the rationing that took place between 1991 and 1992, due to the dramatic decrease in reservoir levels caused by a very long ENSO (El Niño Southern Oscillation), it became obvious that the country's dependence on water sources, coupled with a geographic location that made it vulnerable to the ENSO, meant that another rationing could eventually take place unless changes were made.

Evidently, the system would need some backup capacity which would only be dispatched under critical circumstances, due to its higher variable costs. However, this meant that such generators would have to be built beforehand and would only be used every 3 to 5 years. This clearly meant that such units would have a hard time recovering their fixed costs, with incomes coming only once every few years. No reasonable investor would put his money in a project that could not, at least, recover its fixed costs. As mentioned before,

\footnotetext{
* The authors would like to thank Oscar Martinez and Nelson Guauque for their help as well as professors Shmuel Oren and peter Cramton for their valuable insight.

${ }^{\dagger}$ Corresponding author. Tel.: (571) 3394949 ext. 2883.

E-mail address: jvillarr@uniandes.edu.co; c-soto@uniandes.edu.co.
} 
the State could not build these plants, so the question became about generating the right incentives. The first obvious answer was to create a Capacity Charge that would be equal the fixed costs of a peaking unit and would be given to all those who helped ensure the system's reliability. This meant that the regulator would administratively determine how much should be paid to each generator.

Although the system appears to have worked, as there have not been any rationing events since the last one was implemented in 1997, there are many questions about its true effectiveness and the cost it entails. Many countries have been trying out different ways of ensuring generation adequacy through market mechanisms and these methods have clearly caught the attention of the Colombian regulator. The choice seems to be a reliability call option, similar to the one the University of Comillas ${ }^{[7]}$ proposed in the year 2000 as well as Oren $^{[9]}$, which would have firm energy as the underlying asset. The proposal appears to make sense for the Colombian system, particularly since the critical event in Colombia is characterized by a severe reduction of the available energy, in the form of depleting reservoirs during severely dry periods, and not by a lack of capacity to supply peak demand.

Although Colombia is not the only country facing the dilemma of the best way to ensure generation adequacy, the peculiar characteristics of the Colombian system imply that the solution has to be unique. The following study evaluates how such mechanism would work in the Colombian system.

\section{Evaluation of the current model}

As the discussion about the current method progresses, there have been many comments regarding the effectiveness of the current Capacity Charge. As it is well known, rationing was avoided during the last ENSO which hit the system between 1997 and 1998 and, although many claim that this is evidence that the Capacity Charge worked, the reality is much different. Firstly, the Capacity Charge had just been implemented in January 1997, a few months before the ENSO struck. Knowing that it is impossible to plan and build a generating plant in just a few months, it was quite clear that the mechanism could not have helped avoid rationing during that period. Furthermore, Wolak ${ }^{[4]}$ states that during a meeting with Colombian stakeholders, many mentioned that there was uncertainty about the system's ability to overcome a future ENSO event without rationing.

However, many of the comments made about the current mechanism have to do with its ability to reach the social optimum. It is well known that, given the variable nature of the demand for electricity and its nonstorability, the ideal technology mix is one that includes all different types of generators as a function of their fixed and variable costs. This means that peaking units with high variable costs are desirable as they are ideal suppliers during peak demand. This means that there should not be any bias in favor or against any type of technology in the market so as to achieve the ideal mix of technologies.

This, however, has not been the case in Colombia with the current Capacity Charge. As mentioned before, the Capacity Charge is given to all those who commit their capacity to the system's reliability; the system operator runs a simulation in which it determines the capacity requirements under a critical situation and contracts this capacity among the existing plants. Since the existing capacity is expected to be greater than the demand, the system operator will contract the capacity, favoring those with the least variable costs until the requirements are met. In other words, those with lower variable costs will have a greater chance of gaining the Capacity Charge, while peaking units with high variable costs may be left out. This is a clear incentive for entrants to invest in projects that will ensure the Capacity Charge. It has to be said that if reliability and hedging against rationing caused by the ENSO are to be achieved, peaking units with high variable costs are ideal for reaching this objective thanks to their low installation costs.

There seems to be evidence that many peaking units have made investments in order to become more efficient (lower variable cost) Combined Cycle Gas Turbine generators, looking only to ensure the income generated by the Capacity Charge, despite such investments not necessarily being needed by the system. As more and more capacity becomes low variable cost capacity, the spot prices are depressed and the existence of the peaking units is further jeopardized.

Another issue is related to the benefits that the consumer gets for paying for the Capacity Charge. As Vazquez et al ${ }^{[10]}$ mention, consumers are uncertain about what they are paying for and what they are entitled 
to. It would seem that consumers are only paying for the existence of the generating capacity. However, should they be entitled to something more? As Oren ${ }^{[8]}$ mentions, in an Energy Only Market, the incentives for expansion come from the scarcity rents; these rents will only be captured by those who are installed and can generate when the event happens, therefore, agents will want to capture these rents and will invest in new generating capacity. Likewise, if there is excess generating capacity, there won't be any scarcity rents, meaning that there won't be any new capacity installed. However, there may be certain risk adverse agents who would be willing to trade these uncertain rents for a fixed income, in which case they might want to sell call options in exchange for the option premium. This would mean that the incentives for new installation should come from the scarcity rents $\boldsymbol{o r}$ the premiums generated by some reliability charge, but there should not be a double incentive. This means that those generators that commit their capacity and receive a premium should not be allowed to capture the scarcity rents. One could even ask if there should be scarcity rents at all in a system that has a capacity charge; if the mechanism works, and effectively ensures the system's reliability, there should be no scarcity hence no scarcity rents either. This, however, has not been the case in Colombia where during the last ENSO, those who received the Capacity Charge also captured the scarcity rents that were present during this period as the following Fig. 1 with the average monthly electricity spot prices show:

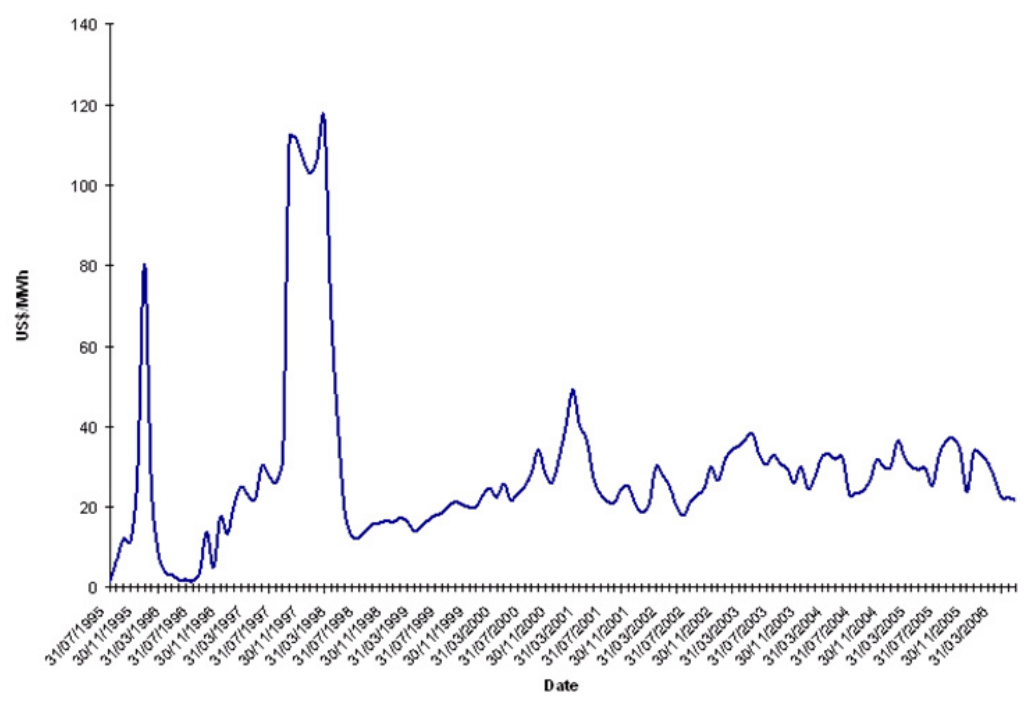

Fig. 1. Average spot prices in US\$/MWh in constant prices of July 2006

It is pretty clear that not only did the generators earn the Capacity Charge during the last ENSO (19971998), but they also gained a considerable amount of money thanks to the scarcity rents that appeared during that period.

The issue is further aggravated by indications that those who receive the Capacity Charge may not be available during a critical event and their penalty, if any, would only be to lose the Capacity Charge they had previously earned. Ayala et al. ${ }^{[1]}$ mentions that this in fact happened during the last ENSO event and that it was those generators who did not earn any Capacity Charge the ones who actually "saved the day". Oren ${ }^{[8]}$ puts the Colombian example as one of a system where those earning Capacity Charge may not be available while those that were left out could end up guaranteeing the reliability of the system.

A well informed consumer might wonder if the deal is fair. Once again, what is he paying for? Reliability that he may not actually get and no real protection against scarcity rents. The situation would be similar to buying auto-insurance only to find out that the agreement does not guarantee that the resources for a repair will be available when needed, and that in any case, should the car be repaired, the consumer will have to pay the bill himself.

The consumer might also wonder if he really wants to pay for "capacity". After all, capacity is only as good as the energy it produces; therefore capacity unable to generate electricity is of no use to the consumer. This raises the question about the type of product a reliability charge should pay for. Certainly in predominantly thermo/nuclear systems like those found in the US and Europe, ensuring capacity is almost the same as 
ensuring energy because, as long as the fuel is available, these types of generating technologies can produce close to their nameplate capacity when needed. The situation, however, is quite different in systems where Hydro power is the predominant technology; the generating capacity of a hydro plant is useless if there is no water with which to generate electricity, and unlike the thermal unit, its fuel (water) can't just be bought in the market. Thus, there could be a situation where there might be enough capacity to supply peak demand during a scarcity period but not enough energy.

Furthermore, unlike US or European systems which have to hedge against demand-side shocks, mainly during the summer and winter, when the demand for cooling or heating rises accordingly, the Colombian system is subject to severe supply-side shocks.

The question therefore is what type of event the system is hedging against and what the product is that the consumer should buy. The answer for the Colombian system is simple: The system needs to hedge against a long run event that causes severe supply side shocks, represented in a dramatic decrease of the generating resources, which means that there may not be enough energy to supply the demand. Therefore what is needed is a mechanism that ensures that there will be enough available energy to supply the demand during these critical periods.

Furthermore, consumers deserve something more in return for the money they are paying for reliability and there should be no room for double incentives or double payments, while still creating the appropriate motivation for investment in backup capacity by reducing the financial risk that these backup units usually face. In other words, a joint risk agreement whereby the consumer will pay the generator a premium to hedge against rationing and scarcity rents in exchange for reducing the investment risk of backup units.

The ideal solution to such a question may seem obvious to those who have experience with financial derivatives; guaranteeing the supply of the underlying asset, that may be needed only under certain circumstances, at a price not higher than a certain level in exchange for a premium. An option would be the instrument the regulator is looking for.

\section{The new market-based proposal}

As mentioned before, given the requirements of the Colombian system, the answer was a call option. This scheme was proposed by the regulator in December 2005, which was based on a study made by the University of Comillas in $2000^{[7]}$. Under the new scheme, the regulator would buy call options for all of the expected demand. The premiums of the options would be subject to an auction where generators would commit all their firm energy under a critical situation at a given price (the strike price). The value of the option would be equal to the scarcity rents that the generator would give up by holding the call option, as well as the expected penalties should he be unavailable during a period when the options are being exercised and, if needed, the fixed cost that a generator would need to ensure to start a new project.

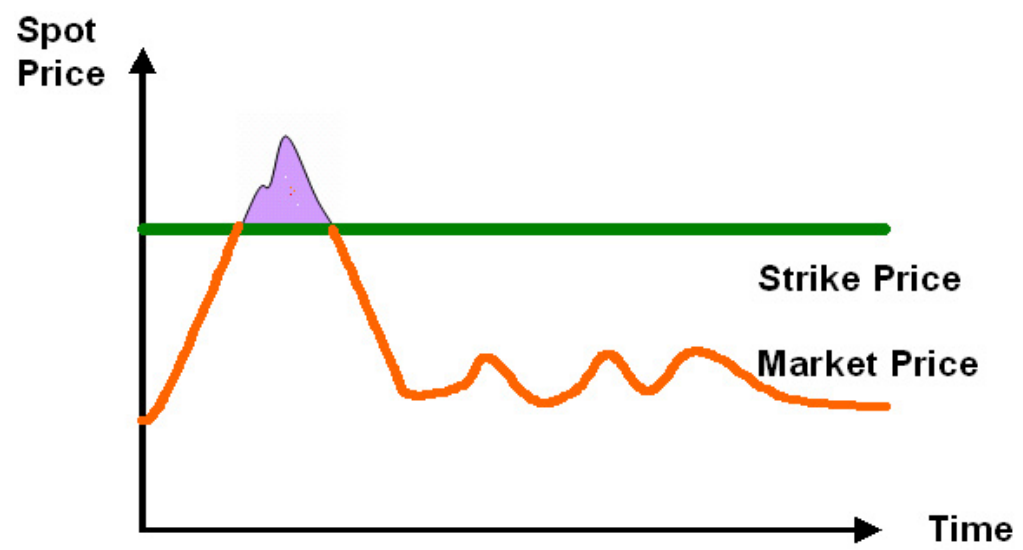

Fig. 2. Call option scheme 
The previous Fig. 2 shows how the option would work; if the spot price is below the strike price, the options won't be exercised and the generator can sell his energy in the market at any price. However, if the spot price rises above the strike price, the options are exercised and those who sold them are forced to sell the energy they committed at the strike price. Those generators who are unable to fulfill their obligations will be forced to pay some sort of compensation for the cost that such failure will have on the system. This compensation could either be an explicit penalty for non compliance or the generators may be forced to buy the energy they lack in the market at prices which are higher than the strike price.

It is worth noting that this penalty gives a clear incentive for the generators to ensure they are available and are able to produce the energy they have committed. The penalties also relieve the regulator of the burden of having to determine if a generator was unavailable due to just causes or if it is simply trying to withhold capacity. The penalty will be charged no matter the reasons the generator gives for his unavailability.

Also, new generators, particularly peaking units, may want to ensure a certain amount of income before starting to build a new plant. If this is the case, they can add this value to the premiums they will submit to the auction, and if they succeed, they will build the new project or otherwise they can scrap it.

Therefore, according to [7], the valuation of the premium that each generator will charge will be:

$$
P=E\left[\int_{\rho>k}(1-\lambda)(p-k) d t\right]+E\left[\int_{\rho>k}(p-k+p e n) d t\right] .
$$

The term $\lambda$ is the probability of failure of the generator. The first term corresponds to the expected scarcity rents the generator will forfeit because of his position in the call option, should he be available with a probability of $(1-\lambda)$. The second term is the scarcity rents he will waive plus the expected penalties he will have to pay when he is not available with a probability of $\lambda$. The sum of these two will equal the premium that the generator will bid in the auction. From Fig. 2 , the premium will be equal to the purple area plus the expected penalties.

There is a clear incentive to increase the reliability of the plant as a smaller probability of failure $(\lambda)$, will mean that the generator could auction a smaller premium and, therefore, have higher chance of being successful in the auction.

However, if the entire expected demand is covered by these options, why would the spot price be higher than the strike price? The only reason would be that certain generators are in non compliance of their obligations meaning that other agents who did not receive any premiums can now capture some scarcity rents and sell at prices above the strike price.

It is worth noting that this mechanism acknowledges the possible existence of scarcity rents, even if the whole of the demand is contracted in reliability obligations. However, unlike the Capacity Charge, only those that did not receive any type of reliability payment would be allowed to capture these scarcity rents while the rest would have to settle for the strike price.

This means that, unlike what some generators have stated, the reliability option interferes neither with the spot market nor with the bilateral contracting; as prices could eventually rise above the strike price and bilateral contracts will hedge against market prices until the strike price is reached. The reliability option is nothing more than a mandatory hedge against prices higher than the strike prices with an obligation of delivery of the underlying asset (firm energy).

The call reliability option is coherent with the "reliability as a public good and energy as a private one" as the regulator is contracting all of the expected demand, hence seeking the reliability of the system explicitly.

Also, the consumer would be receiving something in return for his money as his reliability needs are met and he is also covered against high prices.

\subsection{The meaning of the strike price}

One of the fundamental parameters of the reliability option is determining the strike price of the option. As mentioned before, what is needed in Colombia is a mechanism that hedges against the critical event (ENSO). However, it should not hedge against the prices that may arise as a consequence of the momentary conditions of the system. The strike price should therefore only reflect a critical situation. However, the question is how the spot price would reflect such an event. As it is well known, if the market is a competitive one, 
each agent's offer will be equal to his variable costs. For thermo generators the variable costs are easily determined, as they are mainly the costs of fuel and efficiency of each technology. For the hydro units however, the variable costs are equal to the opportunity costs of water, which, depending on the reservoir capacity and the water availability each generator has, should be smaller than the variable costs of the thermo units.

However, the situation changes dramatically under an ENSO event. The variable costs of the thermo units could increase as the higher demand for fuel might translate into either a rise in fuel prices or some generators being forced to use other more expensive fuels. On the other hand, depending on the severity and length of the ENSO, many hydro generators could see their reservoir levels depleted, causing the opportunity price of water to skyrocket. This would mean that these generators which were previously the cheapest to dispatch could now become the most expensive. If the critical event is not serious enough to require hydro generators with high water opportunity costs, spot prices should not rise significantly. However, if the event is serious enough to require that even hydro generators with high opportunity costs be dispatched, the spot price would rise to reflect such costs.

This means that a severe ENSO event will cause the water levels to decrease which will in turn increase the opportunity price of water which, under scarcity conditions, will cause the spot price to increase until this opportunity cost is reflected in it. The strike price should therefore be placed at a level that reflects this situation.

\subsection{Expected revenue under the new scheme}

The following seeks to obtain an approximation of the amount of money that would be transferred under the new scheme. It is worth noting that this is not meant to be a rigorous price simulation model or a valuation one. However, it might give some insight into the importance of each variable as well as obtaining a reasonable approximation to the expected payments under the new scheme.

As it is well known, the valuation of derivatives for the electricity market presents certain challenges as electricity prices do not comply with many of the assumptions made by such models as the Black-Scholes or the Cox-Ross-Rubinstein model for option valuation. Chief among these challenges is that electricity prices are not normally distributed and do not follow a simple Brownian motion.

Also, as Lucia et a ${ }^{[6]}$ point out, arbitrage in space and time is difficult with electricity as it is not storable and the restrictions within the transmission grid mean that it cannot necessarily be taken to where it is needed. This means that the spot price may not contain all the information regarding future expectations, as the spot price would only reflect spot supply and demand conditions.

However, simulation methods have been developed to value derivatives under such circumstances. The model most commonly used in the electricity sector is the Jump diffusion model with mean reversion as [6] states.

A mean reversion process is described by the following equation ${ }^{[3]}$ :

$$
S_{t+1}-S_{t}=\alpha\left(S^{*}-S_{t}\right)+\sigma \varepsilon_{\tau} \sqrt{\Delta t} .
$$

The left-hand side of the equation represents the price change from t to $t+1$ while the first part of the right-hand side is the mean reversion component and the second part is the diffusion component. Here $\alpha$ represents the mean reversion rate, $S^{*}$ is the long run equilibrium price, $\sigma$ is the volatility and $\varepsilon$ is the random variable. Using the procedure given in [3] and the average spot daily price series for base load from 1997 to 2005 (at constant 2003 prices) the following values are found:

$$
S^{*}=54.022 ; \quad \alpha=0.06798 ; \quad \sigma=2.08965 .
$$

The price returns are then fitted to a probability distribution as follows:

The best fit is achieved with a t-student distribution with a mean of 0 , a scale factor of 0.05 and 1.583 degrees of freedom. It is worth noting that although the fit is not perfect, it is close enough for the purpose of this study which, as previously mentioned, is not to develop a rigorous price simulation model.

Using the previous data, one can proceed to make the simulation for a 5 year period, which is the auction period originally suggested by the regulator. The results are as follows: 


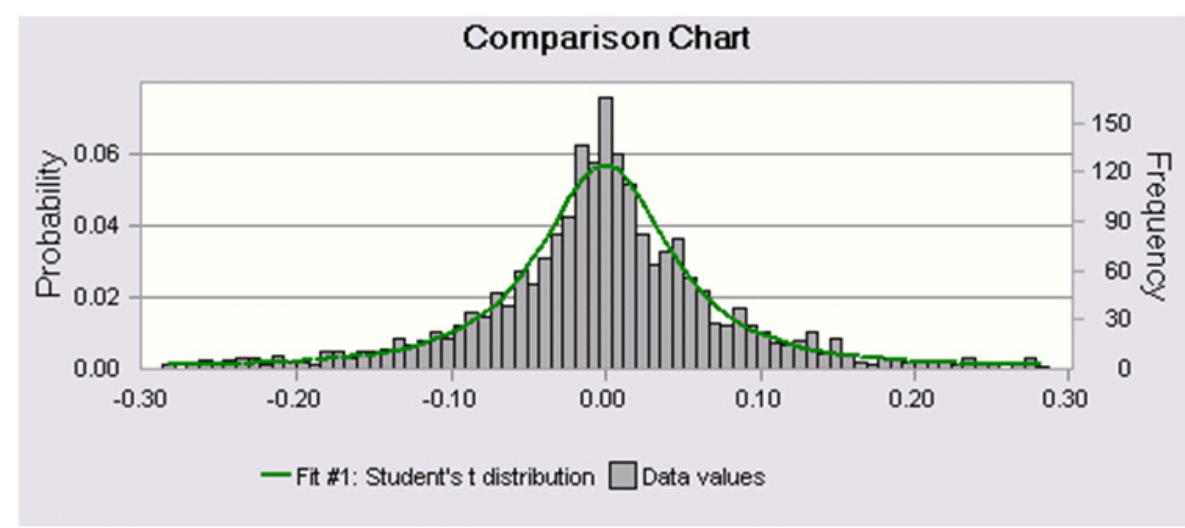

Fig. 3. Daily returns fit

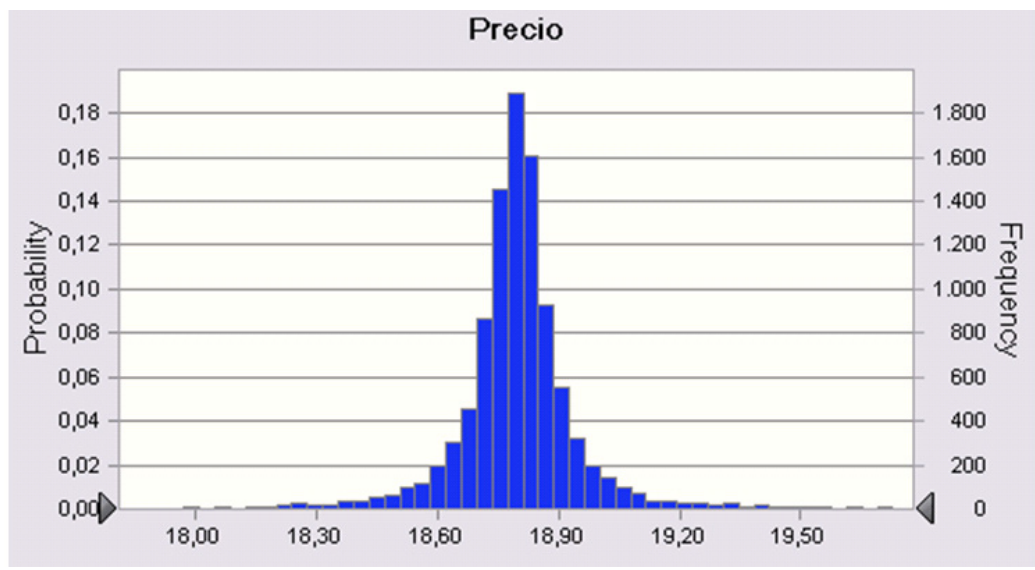

Fig. 4. Price simulation using a mean reversion process

As expected, the price revolves around the long run equilibrium price. However, this model does not include the jumps that an ENSO event would have caused. Therefore, the valuation of any option under the previous model would be 0 as it would never have been exercised. This means that the mean reversion model is not sufficient and the effect of jumps must be taken into consideration, like the jump diffusion with mean reversion model.

The mathematical expression that explains this process is given by the following equation ${ }^{[2]}$ :

$$
S_{t+1}-S_{t}=\alpha\left(S^{*}-S_{t}\right) \Delta t+S_{t} \sigma \varepsilon_{\tau} \sqrt{\Delta t}+\eta\left[S_{t}\left(k+\delta \varepsilon_{2 t}\right)\right] .
$$

The first part of the previous equation is the same as that of the mean reversion process but with an additional term which includes the jump component. Here $\eta$ is a value equal to 0 or 1 with a given probability, $k$ is the probability of the jump, $\delta$ the volatility of the jump and $\varepsilon_{2 t}$ is the random jump component.

To obtain the probability of a jump, one must find the probability of an ENSO event. The National Weather Service Climate Prediction Center has a series of records in which ENSO events have been documented since $1951^{3}$. According to this source, an ENSO phenomenon occurs when there are 5 consecutive months of positive SST anomalies. After studying the information it was found that out of the 678 months for which there was data available, 167 were considered ENSO months. Therefore the probability of an ENSO (jump) would be $24.63 \%$

Initially $k$ and $\delta$ will be determined using the information available for the last jump in the price series which corresponds to the years 1997 and 1998. This gives values of 3.92 and $16.92 \%$ respectively. The fit for the jump distribution is found following the same procedure as before. This gives a fit to a t-student distribution with a scale factor of 0.07 and 1.311 degrees of freedom. With this additional information the simulation is run and the following results are obtained:

\footnotetext{
${ }^{3}$ See http://www.cpc.ncep.noaa.gov/products/analysis_monitoring/ensostuff/ensoyears.shtml.
} 


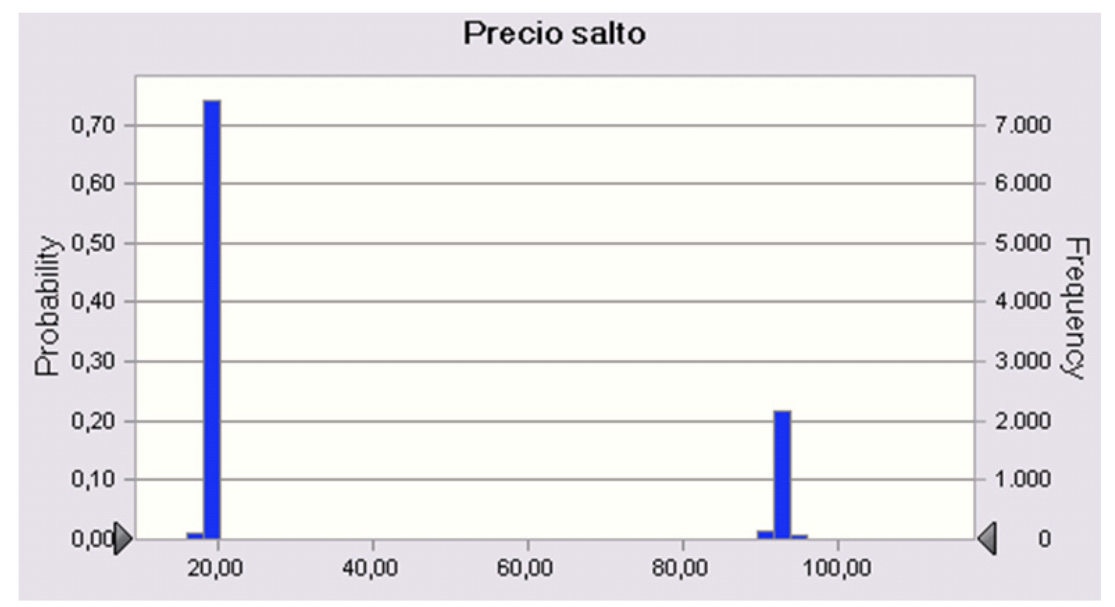

Fig. 5. Price simulation with jump diffusion

As expected, most prices will be found around the long run equilibrium price. However, there are high prices which reflect the occurrence of a jump and, based on these prices, the option premium will be calculated as the expected payoff for the option which is:

$$
\text { rent }=\max (0, p-k) .
$$

The strike price $(k)$ that will be used will be the one suggested by [7] which was of COP $\$ 130 / \mathrm{kWh}$ in the year 2000, equal to US\$69.6/MWh in 2006 money. Therefore, the simulation of the option payout produces the following results:

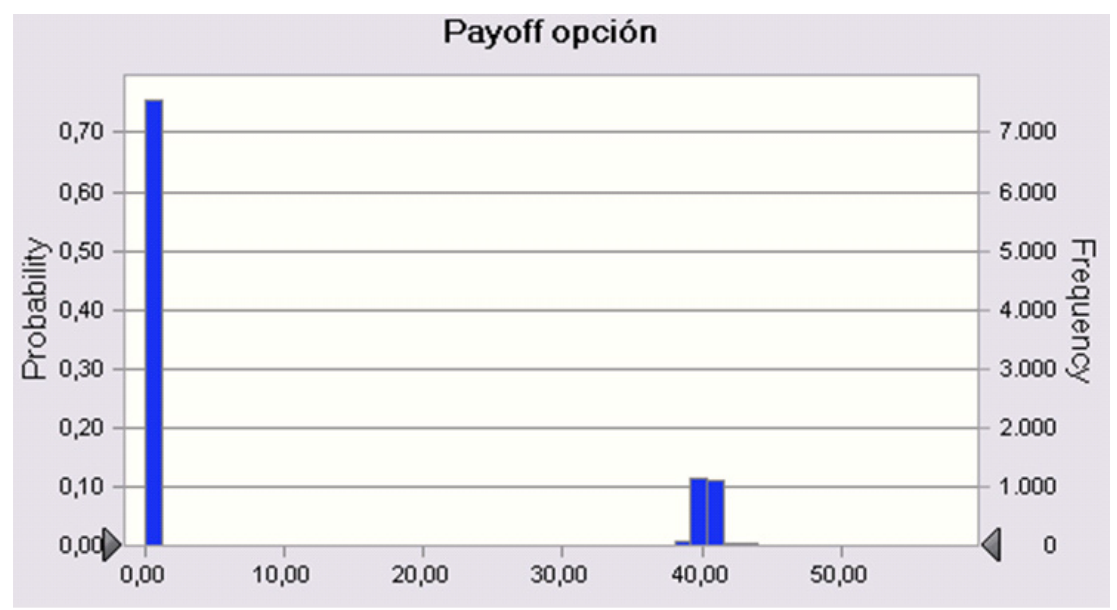

Fig. 6. Option payoff simulation

The resulting premium is US\$9.83/MWh. With this value, the total payments that will have to be made correspond to this premium coupled with the expected demand in 4 years time (2010). The demand projections can be found in the report made by the Mining and Energy Planning Unit (UPME) ${ }^{[11]}$ and are the following:

To these values of expected demand, a 5\% margin is added, as it is done in the current Capacity Charge system. This means that the total money that will be paid as option premiums for each demand scenario would be:

It should be noted that although these revenues are somewhat higher than those under the current scheme (about US $\$ 500$ million a year), the amount of money that is paid should increase as the demand, and therefore the reliability requirements, increase.

It is important to mention that these premiums do not include the expected penalties for non delivery or the fixed costs that new entrants would include in their premiums. 
Table 1. Demand estimates

\begin{tabular}{c|ccc}
\hline GWh Year & High & Medium & Low \\
\hline 2005 & 48.733 & 48.215 & 47.697 \\
2006 & 50.564 & 49.874 & 49.117 \\
2007 & 52.384 & 51.559 & 50.668 \\
2008 & 54.457 & 53.410 & 52.337 \\
2009 & 56.287 & 55.001 & 53.696 \\
2020 & 58.276 & 56.734 & 55.100 \\
\hline
\end{tabular}

Table 2. Revenues according to the demand scenario

\begin{tabular}{c|ccc}
\hline & High & Medium & Low \\
\hline US\$ & 572.583 .080 & 557.695 .220 & 541.633 .000 \\
\hline
\end{tabular}

One could argue that the events of 1997 and 1998 cannot effectively reflect the price behavior under a critical event. As many have argued, in 1997 and 1998 the market was still very immature and there was significant regulatory intervention which would seem to indicate that these prices may not be an accurate measure. Furthermore, since there are no price series available for other critical events, inferring price behavior from only one set of data may not be appropriate. However, what other way is there of estimating the effect of the jump?

Another approach could be to use the probability of a rationing event taking place. UPME has developed a scheme which allows for rationing to take place when the spot price of electricity exceeds a certain level. There are four steps of rationing; each causing a certain part of the demand to be disconnected according to its priority. The prices for each rationing step are as follows:

Table 3. Rationing costs

\begin{tabular}{c|c}
\hline Cost & US\$MWh \\
\hline CRO1 & 209 \\
$\mathrm{CRO} 2$ & 379 \\
$\mathrm{CRO} 3$ & 665 \\
$\mathrm{CRO} 4$ & 1.316 \\
\hline
\end{tabular}

If there are expectations of a probable supply deficit, there would be a real possibility of the system reaching the first rationing step which would cause the spot price to rise to this level.

Although there have been several rationing instances in the Colombian system, the last being from 1991 to1992, there is not enough information available to accurately calculate the probability of reaching the first or further rationing steps. Therefore, the calculations will be carried out using different probabilities of reaching the first rationing step. To run the simulations the parameter $k$ will change to 8.597 in order to reflect the spot price when the first step of rationing takes place. The results are:

Here both the premiums and total payments that should be made for different probabilities are shown. As expected, the higher the rationing probability the higher the transfers will be. It is worth noting that the results are consistent with the incentives that the market should provide. If the risk of rationing is high, due to low installed capacity, the price of the premiums will rise, generating the incentives needed for additional installation. Likewise, if the installed capacity is high, the risk of rationing will be low as will the premiums; therefore there will be little or no incentives to install new capacity.

The probability of reaching the first step of rationing will depend on the amount of capacity installed, the system's technological composition, the expected increases in demand, the probability of an ENSO and its expected intensity.

It is clear however, that taking into account how much is currently being paid for Capacity Charge (about US $\$ 500 \mathrm{M}$ ), the total payments under a Reliability Options scheme would be similar. It is important to stress that the previously estimated values correspond only to the scarcity rents that the generators would give up because of the reliability option. However, they are free to offer whatever premium they wish, thus, if the 
Table 4. Expected premiums and total revenues

\begin{tabular}{c|c|c|c|c}
\hline $\begin{array}{c}\text { Rationing } \\
\text { Probability }\end{array}$ & $\begin{array}{c}\text { Premium } \\
\text { US\$MWh }\end{array}$ & $\begin{array}{c}\text { Total revenues } \\
\text { MUS\$ High demand }\end{array}$ & $\begin{array}{c}\text { Total revenues } \\
\text { MUS\$ Medium demand }\end{array}$ & $\begin{array}{c}\text { Total revenues } \\
\text { MUS\$ Low demand }\end{array}$ \\
\hline $1 \%$ & 1,01 & 59 & 57 & 56 \\
$2 \%$ & 1,99 & 116 & 113 & 110 \\
$3 \%$ & 3,35 & 195 & 190 & 185 \\
$4 \%$ & 3,85 & 224 & 218 & 212 \\
$5 \%$ & 4,72 & 275 & 268 & 260 \\
$6 \%$ & 5,57 & 325 & 316 & 307 \\
$7 \%$ & 6,37 & 371 & 361 & 351 \\
$8 \%$ & 7,30 & 425 & 414 & 402 \\
$9 \%$ & 8,40 & 490 & 477 & 463 \\
$10 \%$ & 8,76 & 510 & 497 & 483 \\
$11 \%$ & 10,94 & 638 & 621 & 603 \\
$12 \%$ & 11,84 & 690 & 672 & 652 \\
$13 \%$ & 12,83 & 748 & 728 & 707 \\
$14 \%$ & 13,30 & 775 & 755 & 733 \\
$15 \%$ & 14,41 & 840 & 818 & 794 \\
\hline
\end{tabular}

premium that the previous valuation provided is not high enough to start a new project, the entrants will be free to offer the premium necessary to build a new plant and, if this bid is accepted, it would be because this new project is in fact needed. This means that it is still the market which determines the amount of capacity needed as well as the reliability price.

However, as previously mentioned, these price simulation models offer only a reasonable estimate of the premium values that may be expected as well as outlining how the option valuation could be made. A more rigorous price simulation model should also model the expected behavior of the ENSO and its impact. As it was previously mentioned, an ENSO event is measured as 5 consecutive months of variations of over $0.5^{\circ} \mathrm{C}$ in the Oceanic Niño Index (ONI). From the following graph of the ONI from 1990 to present day, it is clear that it should not only be taken into account the occurrence of an ENSO event but also its intensity and duration. Since the year 2003 ENSO events went unnoticed in the Colombian system, so it is also worth taking into account its expected impact on any specific region.

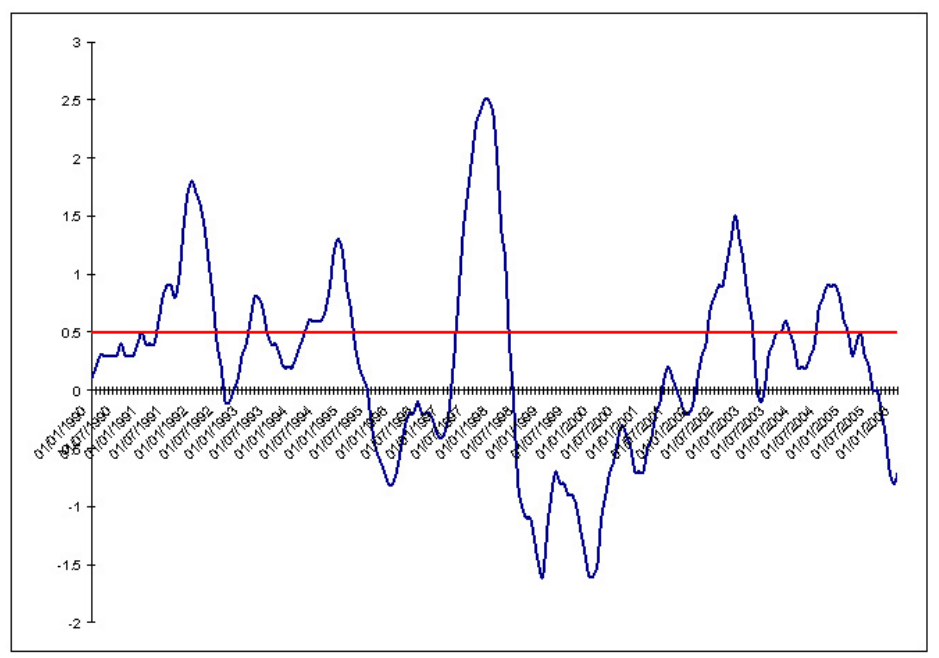

Fig. 7. Behavior of ENSO 


\subsection{Expected premium prices}

As previously stated the premiums that each generator would bid are free and would probably include the valuation of the scarcity rents, the expected penalties, and in the case of new generation projects, the additional fixed costs that should be recovered in the auction in order to build the new plant. Therefore, according to [7] the offer made by an entrant would be:

$$
P=E\left[\int_{p>k}(1-\lambda)(p-k) d t\right]+E\left[\int_{p>K} \lambda(p-k+p e n) d t\right]+C F
$$

However, what would the maximum additional value that an entrant would include in his bid to cover his fixed costs $(C F)$ be?

It is clear from the previous equation that incumbents, who have already recovered all of their fixed costs, will bid the lowest premiums as they are only valuing the scarcity rents and the expected penalties, therefore, should new capacity be needed, the marginal offer will be that of a new generator.

Different technologies with different fixed costs would mean that different offers would be made according to the type of project that is to be undertaken. However, technologies with higher fixed costs should benefit from the inframarginal rents they will gain thanks to their lower variable costs.

So, which fixed costs would the entrant add to his offer? Suppose that there are two technologies with $C F_{1}>C F_{2}$ and $C V_{1}<C V_{2}$. Two investors are planning on building new plants and have the chance of bidding a premium that includes $C F_{1}$ or $C F_{2}$. Since the strike price is fixed, the valuation of the scarcity rents is identical for the two agents. Also, since they are new generators their expected penalties due to outages should be the same. Therefore, the only difference in their bid should come from the value $C F$.

On the other hand, the system operator needs an additional $q$ of firm energy in the auction process that can only be supplied by a new project. The system operator will take the lowest offer that allows it to ensure $q$. In case of a tie, each new generator will be paid the clearing price for $q / 2$. Also, it is better to receive the premium corresponding to $q$ of the lowest fixed cost technology than $q / 2$ of the technology with the highest fixed costs ${ }^{4}$. That is:

$$
C F_{1} q>C F_{2} q ;<C F_{2} q
$$

Since the entrants will want to maximize their benefits, they will offer a value of $C F$ that maximizes the value of the premiums they will receive. That is, they will want to maximize:

$$
\operatorname{Max} E\left[C F_{i} \times q_{i}\right]
$$

where $C F_{i}$ is the $C F$ that the agent $i$ would bid and $q_{i}$ will be the fraction of $q$ that would be assigned to him. Therefore the payoff matrix for each agent would be:

Table 5. Payoff matrix

\begin{tabular}{c|c|c|c}
\hline \multicolumn{2}{c|}{} & \multicolumn{2}{|c}{$\widehat{2}$} \\
\cline { 3 - 4 } \multirow{2}{*}{$\hat{1}$} & $C F_{1}$ & $\left(C F_{1} \frac{q}{2}, C F_{1} \frac{q}{2}\right)$ & $\left(0, C F_{2} q\right)$ \\
\cline { 2 - 4 } & $C F_{2}$ & $\left(C F_{2} q, 0\right)$ & $\left(C F_{2} \frac{q}{2}, C F_{2} \frac{q}{2}\right)$ \\
\hline
\end{tabular}

This is the classical Prisoner's dilemma where both agents would be better off if they cooperated bided $C F_{1}$. However, they both end up bidding $C F_{2}$ (Nash equilibrium).

\footnotetext{
${ }^{4}$ This is a reasonable assumption because, for example, in UPME's expansion plan 2005-2019 the reference installation costs of a simple cycle gas turbine with a capacity of $150 \mathrm{MW}$, considered as a backup plant, is US\$74'252.925 or US\$495.019/MW while a combined cycle gas turbine with a capacity of 200MW costs US\$140'057.248 or US\$700.286/MW.
} 
The previous result has important implications. In a competitive market that has no entry barriers, entrants would bid a premium corresponding to that needed to build a plant with the lowest fixed costs, regardless of the technology that will actually be built.

Higher cost technologies would still be built, even if they only receive the fixed cost of a cheaper technology, as they would recover the rest through the inframarginal rents that their lower variable costs imply. This would be consistent with the principle of a mechanism that seeks to ensure that there is enough backup capacity to hedge against a critical event.

However, could an incumbent bid a higher premium than an entrant? From the premium equation for an entrant we have that:

$$
\begin{aligned}
& P=E\left[\int_{p>k}(1-\lambda)(p-k) d t\right]+E\left[\int_{p>K} \lambda(p-k+\text { pen }) d t\right]+C F \\
& P=E\left[\int_{p>k}[(1-\lambda)(p-k)+\lambda(p-k+\text { pen })] d t\right]+C F \\
& P=E\left[\int_{p>k}[(1-\lambda)(p-k)+\lambda(p-k)+\lambda(\text { pen })] d t\right]+C F \\
& P=E\left[\int_{p>k}[(1-\lambda+\lambda)(p-k)+\lambda(\text { pen })] d t\right]+C F \\
& P=E\left[\int_{p>k}[(p-k)+\lambda(\text { pen })] d t\right]+C F \\
& P=E\left[\int_{p>k}(p-k) d t\right]+E\left[\int_{p>k} \lambda(\text { pen }) d t\right]+C F \\
& P=E\left[\int_{p>k}(p-k) d t\right]+\lambda \times \text { pen } \times \Delta t+C F
\end{aligned}
$$

The term $\Delta t$ corresponds to the expected period in which the options will be exercised. Hence, the term $\lambda \times$ pen $\times \Delta t$ is the expected value of the penalties that would have to be paid.

There are two generators, a new one $N$ and an existing one $E$, both with the same variable costs and therefore competing for the same dispatch. As previously mentioned $C F E=0$. The objective will be to find the conditions under which the existing generator would bid a higher value than a new one. Therefore:

$$
\begin{aligned}
& E\left[\int_{p>k}(p-k) d t\right]+\lambda_{E} \times p e n \times \Delta t>E\left[\int_{p>k}(p-k) d t\right]+\lambda_{N} \times p e n \times \Delta t+C F_{N} \\
& \lambda_{E} \times p e n \times \Delta t>\lambda_{N} \times p e n \times \Delta t+C F_{N} \\
& E\left[\text { pen }_{E}\right]>E\left[\text { pen }_{N}\right]+C F_{N}
\end{aligned}
$$

Since the strike price is the same for both generators, the valuation of the scarcity rents is the same for both. The previous result means that the only condition under which an existing generator would bid a higher premium than a new one would be if the expected penalties for the incumbent were higher than the expected penalties for a new generator plus the fixed costs he will need to recover in order to build a new plant. This has important implications because it gives the incentives for a new generator to replace an existing one if the cost of building a new plant is lower than the cost to society of the lack of reliability of the existing generator. Also, the marginal price of the auction will still be the one previously found for a new entrant.

\subsection{Expected premium prices}

It was originally suggested that there should be two separate option markets for new and existing generators. It was argued that new generators would need to ensure their income for a longer period of time than the existing generators that had already recovered their fixed costs, which would mean that a different market would have to be set-up. However, such a scheme may facilitate the use of market power by the incumbents.

As previously mentioned, a market with no entry barriers will ensure that the entrants will bid the highest premium. This will help rationalize the behavior of the existing generators. However, suppose that the system operator has to ensure a quantity $Q$ through a reliability auction among the generators $q_{1}, q_{2}, q_{3}, \cdots, q_{n}$. The system's composition is such that: 


$$
Q_{\text {Installed }}=\sum_{i=1}^{n} q_{i}>Q,
$$

Nevertheless, there is a generator $q_{x}$ with a capacity large enough such that:

$$
Q_{\text {Installed }}-q_{x}<Q
$$

This means that $q_{x}$ is an "essential" generator, and the system operator will require his capacity in order to ensure that the quantity $\mathrm{Q}$ is acquired. This means that the system operator will have to accept $q_{x}$ 's offer regardless of how high it is ${ }^{5}$.

The situation would be different with a market in which both existing and new generators compete against each other. As previously mentioned, the maximum offer under such market will be the one given by (5). If an existing generator decided to bid a higher premium, new entrants would cover the shortfall that the removal of the existing generator would cause. Hence, the existing generator would be forced to rationalize his offer to ensure that he is able to sell option contracts and receive the income this would generate.

\subsection{Costs under a reliability options scheme}

Some have argued that the reliability option is the most expensive way to ensure the system's reliability. That it would be better to have a separate reliability auction and leave the price hedging to the bilateral contracts that are currently being traded. However, is this a valid argument?

It has been argued that all of the current demand is hedged against high prices thanks to the bilateral contracts and that a mandatory hedge with a reliability option would only increase prices for the consumer. Let us assume that this is true and that all of the demand is hedged against high prices. This means that consumers will have a payoff profile like the following:

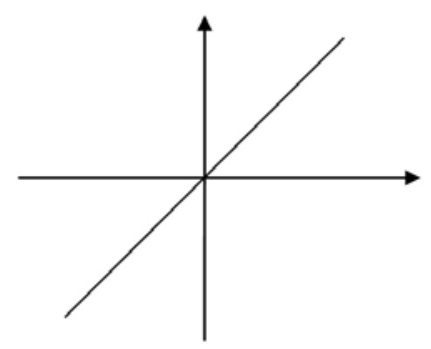

Fig. 8. Bilateral contract payoff

Under the proposed scheme the bilateral contracts would only cover up until the time the strike price is reached, as the reliability option would cover against higher prices. This means that the new bilateral contracts would have the following payoff profile:

Clearly the value of this new contract is lower than the original but, how much lower? If there are no chances of arbitrage two assets that offer the same payments under the same contingencies should be worth exactly the same. Therefore the value of the new contract for the consumer will be that of a synthetic portfolio made out of a long position in a forward and a short position in a call option with the following payoff profile:

In other words, the value of the new contracts would be:

$$
\text { Value }_{\text {Bounded }} \text { forward }=\text { Value }_{\text {Forward }}-\text { Value }_{\text {Call }}
$$

This would be the price that the consumer would pay for the new contract. However, the reliability option is not free of charge which means that the consumer would also have a long position in the reliability option with the following payoff profile:

\footnotetext{
${ }^{5}$ Alfredo Garcia et al. ${ }^{[5]}$ demonstrates that under such a scenario, an auction with a price cap will always clear at this price because the essential generator, conscious of his position, will always bid this price cap knowing in advance that his offer will have to be accepted.
} 


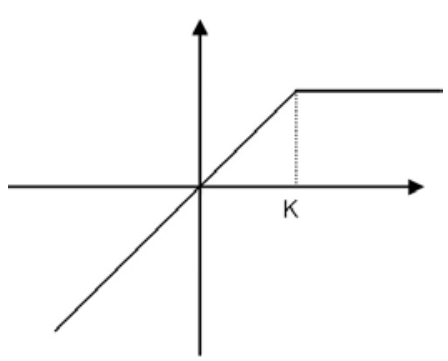

Fig. 9. Bounded bilateral contract payoff

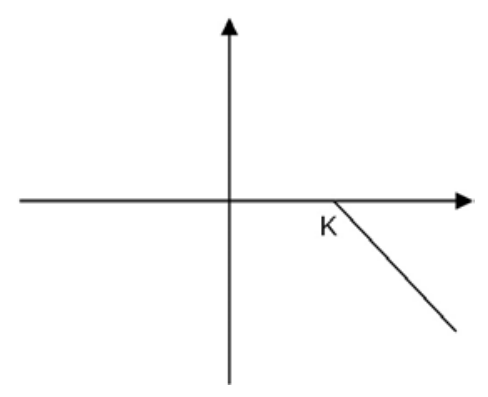

Fig. 10. Short call option payoff

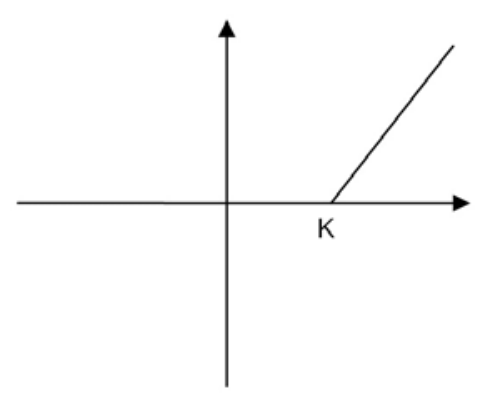

Fig. 11. Long call option payoff

In other words, the consumer has a long position in the forward "bound" contract and also a long position in the reliability option. Therefore, the total cost for the consumer will be:

$$
\begin{aligned}
& \text { Value }_{\text {consumer }}=\text { Value }_{\text {Forward }} \text { Bound } \\
& \text { Value }_{\text {consumer }}=\text { Value }_{\text {Forward }}-\text { Valiability option }_{\text {Call }}+\text { Value }_{\text {reliability option }} \\
& \text { Value }_{\text {Forward }}-\text { Value }_{\text {Call }}=\text { Value }_{\text {reliability option }} \\
& \text { Value }_{\text {consumer }}=\text { Value }_{\text {Forward }}
\end{aligned}
$$

This means that if all of the demand is really hedged against high prices through bilateral contracts, the price including the new reliability option will be exactly the same as the previous price which did not in fact include the option.

\section{Conclusions}

Ensuring generation adequacy has been as much an issue in Colombia as it has been in the rest of the world. However, while for most systems the issue has been about ensuring that there is enough capacity available to guarantee adequate supply during peak demand, the Colombian system is faced with the need to ensure that there is enough energy available during periods of severe drought which are unpredictable.

Although administrative mechanisms to ensure the system's reliability seem to have achieved their objective (though that in itself is a highly contentious subject), there are great doubts about their efficiency. 
Nevertheless, a move to energy only market mechanisms may also prove to be very hazardous as the problems that they have encountered in other countries could be further aggravated by the special characteristics of the Colombian system. The compromise solution, a capacity market, also seems inappropriate given the fact that Colombia's problems are not capacity but energy related.

Market mechanisms seem to provide the best of both worlds; guaranteeing the appropriate amount of reliability at an efficient price given the right performance incentives while ensuring the required quantities in an administrative way. Taking into consideration that what is needed is enough backup capacity to be installed and available when required, the natural market mechanism would seem to be a call option.

However, despite all of its expectations, such a mechanism remains yet to be implemented, and there is a great deal of uncertainty about it's effectiveness in the real world, particularly in the Colombian system. Notwithstanding, as this study has shown, the mechanism could effectively do a better job than the one in current use, ensuring the system's reliability at an efficient cost. The price will be given by the conditions at the moment of the auction and the forward looking expectations; excessive or deficient supply will decrease or increase the price accordingly providing the appropriate incentives to install new backup capacity only when needed. Furthermore, a call option on the firm energy and not the capacity ensures exactly what the country needs during a critical period. Since the regulator would still be determining the reliability quantities, the whole demand would still be covered and many of the risks of an Energy Only Market would be avoided. Also, given the call option's nature, the mechanism would provide a joint risk agreement between consumers and generators, protecting the former against price spikes as well as reducing the financial risk of the latter.

Given the conditions of the Colombian system and the reliability requirements, it is clear that a reliability call option with firm energy as the underlying asset could achieve the desired objectives.

\section{References}

[1] U. Ayala, M. Jaime. Colombia: Coping with the reform crisis. Inter American development Bank, 2004, 59-161.

[2] C. Blanco, D. Soronow. Jump Difussion processes - Energy price processes used for derivatives pricing \& risk management. in: Commodities now, 2001.

[3] C. Blanco, D. Soronow. Mean reverting processes - Energy price processes used for derivatives pricing \& risk management. in: Commodities now, 2001.

[4] W. Frank. Report on "Proposal for Determining and Assigning the Reliability Charge for the Wholesale Energy Market" and "Electronic system of standardized long-term contracts (sec)". Department of Economics. Stanford University, 2005. Http://www.creg.gov.co.

[5] A. Garcla. Investment Dynamics in Electricity Markets. Working paper, 2005.

[6] L. Julio, S. Eduardo. Electricity prices and power derivatives: Evidence from the Nordic power exchange. University of California, 2000. Http://repositories.cdlib.org/cgi/viewcontent.cgi?article=1061\&context=anderson/fin.

[7] R. Michel, P. Arriaga, et al. Estudio del cargo por capacidad en colombia. Universidad de Comillas, 2000. Http://www.acolgen.org.

[8] S. Oren. Ensuring generation adequacy in competitive electricity markets. University of California at Berkeley, 2003. Http://www.ieor.berkeley.edu/ oren/workingp/adequacy.pdf.

[9] S. Oren. Generation adequacy via Call options obligations: Safe passage to the promised land. The electricity journal, 2005. Http:// stoft.com/metaPage/lib/Oren-2005-09-call-options-obligations.pdf.

[10] M. Rivier, P. Arriaga, et al. A market approach to long-term security of supply. IEE Transactions on power systems, 2001, 17(2): 349-357.

[11] UPME. Plan de expansin de referencia. 2006, 2005-2019. Http://www.upme.gov.co. 